\title{
Dying old - and preferably alone? Agency, resistance and dissent at the end of life
}

\author{
By AlLan KeLLEHEAR*
}

\begin{abstract}
Older people who die alone are commonly portrayed negatively in the academic and popular literature. Dying alone is viewed either as an outcome of anti-social behaviour or the result of family, neighbourhood or social services neglect. The idea that people may be exercising agency, resistance or dissent at the end of life and that they do not want attention from services or the wider community receives little or no consideration. By comparing the community and professional views with those of the elderly about end of life preferences, this paper argues that the academic and community image of the elderly as "victims" has eclipsed the usual ability to see this group in pluralist terms. This stereotype of older people who die alone has negative consequences for sociological and policy analysis.
\end{abstract}

Keywords: older people, dying, alone, end of life care, stereotypes.

\section{Introduction}

This essay reviews the literature on dying old and alone and asks: have we overlooked experiences of agency, resistance and dissent in these examples

*Allan Kellehear, Department of Social \& Policy Sciences, University of Bath, Bath, UK. 
International Journal of Ageing and Later Life

of the end of life? Much of the modest body of research in this area seems to focus on the passivity, disability and even negative deviance of this small but growing group of dying people. This is rather ironic from the point of view of the gerontology literature since so much of this writing has concerned itself with "healthy" or "active" living (Leishman 2008). However, when gerontology writers turn their attention to the end of life of older persons who live and die alone, these ideas of agency quickly submerge under other ideas about loneliness, helplessness or vulnerability.

Reinforcing these ideas are palliative care writers (Gelo 2004; McKee et al. 2007; Roy 2003), who commonly concern themselves with what they see as the importance of "companioning" people at the end of life, with little or no awareness that their company may neither be required nor desired by some older dying people living alone. These palliative care writers, along with many journalists writing about those dying or found dead alone, believe that dying old and alone is self-evidently "bad" for everyone. As Seale $(1995,1996,2004)$ regularly observed, dying old and alone is commonly viewed as a failure of care - from friends, family, neighbours, even by society at large. For many cases of people found dying alone or already dead and alone in their homes, the question and the research into failing social and professional care may indeed be legitimate and proper. However, the aim of this paper is to raise a critical but parallel sociological possibility. I will argue that, from the point of view of at least some of the elderly people dying alone, this form of dying may not represent failures of care but rather individual triumphs of agency, resistance and dissent. Establishing the legitimacy of this critical possibility can create a more discerning sociological and policy space for future end of life care analysis and assessment.

In support of this under-recognized argument I will compare and contrast two sets of literature. I will review the research literature on dying alone and then evaluate this body of work by contrasting this with a review of the research literature on elderly views of their end of life care preferences. I will first begin by explaining what is meant by the phrase "dying alone" and provide some social and demographic context to the people for whom this experience and circumstance apply. This will be followed by a review of the prominent societal and elderly explanations 
Dying old - and preferably alone?

believed to be so crucial to our understanding of this experience. Finally, I will show how the common societal and research understandings of dying alone seem not to accord with the views of the elderly themselves about the end of life more generally. Social explanations not generated from the elderly often take a negative view of living and dying alone obscuring and overwhelming the logical possibility of diversity among older people. This diversity might be expected to include a small, but growing minority of people for whom dying alone - without informal or professional care may be an actively preferred and understandable end of life choice.

\section{What Does "Dying Alone" Mean?}

For the purposes of this discussion, "dying alone" refers simply to an experience of approaching death in a lone residential context. In other words, the dying person does not usually reside with others. Klinenberg (2001: 505) emphasises the importance of distinguishing this "residing without others" with related but quite different experiences such as "being isolated" (limited social ties), "being reclusive" (confining one self to the house) and the most common conflation of "being lonely" (feeling alone). The most common rhetorical feature of the media, professional and some research literature is this latter conflation of "dying alone" with "lonely dying" (see, for examples, Adams \& Johnson 2008; Field 1984; Gelo 2004).

There are serious problems with this common habit of conflating "alone" with "lonely" not the least because, as several researchers have observed in purely theoretical terms, the first experience does not necessarily lead to the second (see Weeks 1994 for an excellent conceptual review). Indeed, being alone may in fact lend itself to very many positive psychological and spiritual experiences (see Hamiltby 2000 for a review of these). Furthermore, the association between "dying alone", having a "lonely death" and this being an indication of a "lonely life" are three independent experiences whose linkages are not empirically established (Howse 1997: 2-3). "Dying alone" does not even mean the dying were isolated (or lonely), and those isolated (or lonely) don't always experience "dying alone" (Adams \& Johnson 2008). 
International Journal of Ageing and Later Life

A further methodological observation important to recognise is that although living alone is a minority experience among the elderly, so too is loneliness (Howse 1997: 6; Victor et al. 2009; although see Elias 1985 for a dissenting view about this). Indeed, there is some evidence that advanced age might be a protective factor against loneliness (Victor et al. 2004). Moreover, an early study by Tunstall (1966: 55) reports that most older people living alone actively prefer to live this way. Finally, Klinenberg (2001: 506) warns us that most of our research about living alone is drawn from those older people willing to participate, who are reasonably active, or may use the participation as a way to alleviate loneliness. The number of isolated and reclusive older people who might tell us a different story about the relationship between being alone and loneliness may be underestimated. In that category, we may know least about those who prefer to be reclusive.

Aside from these broad sociological distinctions, Seale (1995: 383-385) offers several other interpersonal and perceptual distinctions. Dying alone may mean no conscious awareness of either carer or dying party of each other as when a spouse dies while the couple are asleep together; or when carers leave the room for a few minutes and return to find their loved one dead. Sometimes, "dying alone" has been employed to mean dying without kin or kith rather than dying without other human beings present, as when people die with staff present or even with other patients present. Some people occasionally include "dying alone" in hospitals when the dying person is known not to have had any visitors. In these ways, people often die "alone" even in hospitals, hospices or at home with others (Howse 1997: 4). Finally, some people suggest that "everybody dies alone" because only the dying person must face death, not the carers of any stripe, and in that task the dying person is "alone" (Owen 2005: 13). This latter observation refers to the existential nature of dying - further discussion of which is obviously beyond the scope of the present article.

These distinctions are very important to rehearse for they highlight the broad and diverse array of meaning available for rhetorical use by researchers and professionals when discussing the simpler social fact of individuals who live and die without others in their residence. The closely related, but very different meanings of being "lone" and lonely, being "isolated" as a social consequence or being deliberately and preferably 
Dying old - and preferably alone?

"reclusive", and facing death with company (us) or none (them) are ambiguous and regularly subject to subtle and misleading use in this area. To set the stage for further discussion of how these terms and concepts have been used to create a research and popular impression of bad, lonely, regrettable and "preventable" deaths, I will now summarise the current social and demographic context of older people now living - and possibly dying - alone.

\section{Social and Demographic Background}

The people who die alone in the UK represent less than $1 \%$ of all deaths in any one year. About two-thirds of these people were over the age of 70 (Bradshaw et al. 1977; Howse 1997) and had lived alone in their own homes (over 93\%). The figures for this population are approximately the same for the USA (Gurley et al. 1996) or perhaps slightly higher (Klinenberg 2001). Over half of the people who die alone seem to die of circulatory diseases such as heart attacks or strokes, while about 5 or $6 \%$ have suicide as their cause of death. Other causes include accidents, such as falls and accidental poisoning for examples, or respiratory diseases (Bradshaw et al. 1977). These figures are mainly gleaned from studies employing coronial reports. They reflect broader figures about ageing and living alone more generally.

In the UK, although one-person households now comprise about $12 \%$ of the general population (National Statistics 2002a), this rises on average to about half of those in the over 65 age group. Some $32 \%$ of women and $61 \%$ of men over 75 years of age now live alone (Age Concern 2008). Although there are about 1.2 million people in the $85+$ age group in Britain (Leishman 2008), they are also now the fastest growing age group (Dunnel 2008). The levels of solitary living are highest in North-West Europe and lowest in Southern Europe and the USA (Tomassini et al. 2004). The social reasons for the growth of these single-person households generally and single older person households in particular are many.

A decline in marriage and a rise in separation and divorce are said to be one reason (National Statistics 2002b). Other reasons offered include: fragmentation of extended families of migrants; better health and social services making living alone more feasible; and rising levels of home 
International Journal of Ageing and Later Life

ownership (Krivo \& Mutchler 1989). Diversity in cultural attitudes to coresidential living may also play a role (Tomassini et al. 2004). Finally, a widespread desire, especially in societies that encourage and celebrate individual autonomy and independence, may make living alone an extension of the prevailing cultural values. Seale (1996: 80), for example, recorded the common observation made by family and friends of older people's "deep concern" for their own independence.

We have very little information about the kinds of people who were found dead or dying alone. What we know we have gleaned from coronial records, interviews with family and friends, or the reports of emergency services personnel. These all suggest, at least in their introductory remarks, that the social situation of all these people were diverse and included people who were normally active and outgoing, or moderately sociable, to people who were more or less regarded by others as reclusive and private. The actual proportion of those who die alone and were regarded as reclusive or private is unknown or subject to any number of speculations and interpretations. Bradshaw and colleagues' (1977) study of 203 people who were "found dead" suggested that over half of these might be considered reclusive $(36 \%)$ or private $(25 \%)$. Twenty years later a further study of people found dead in their UK homes (Howse 1997) suggested that as little as 16 out of 647 cases might be considered reclusive or very private. A major US study (Klinenberg 2001: 503) that examined the reports of emergency service workers who found people dead during and after a major heat wave in Chicago in 1995 simply observed that "many" police officers described victims as reclusive types. How, then, have these possibly different kinds of people who have died alone been viewed by the professional, academic and lay literature?

\section{Prominent Social Perspectives on "Dying Alone"}

Much of the literature on dying alone or being "found dead" alone is drawn from policy, sociology, anthropology or psychology researchers who quickly move to "identify" one or several social "types". This is a long-standing ethnographic-based habit of the human sciences and a review of these in studies or commentaries about dying alone reveal a common pattern of moral and political views towards people who die 
Dying old - and preferably alone?

alone. Noteworthy is the fact that almost all the "types" identified with lone dying are negative ascriptions. Positive conduct or anecdotes seem either not to attract labels or attract negative ones. For example, in Tunstall's (1966) study, despite documenting the fact that his sample of nearly 200 older people living alone preferred that lifestyle proceeded to spend the remainder of his work describing "the isolated", "the lonely" or "the anomic". There was no attempt to identify any positive "type" in his sample. I identify and discuss more of these typical categories below.

\section{Loners and Lonelies}

I have already identified the palliative care literature as central to promoting the view that dying alone suggests lonely dying. Field (1984) was one of the earliest researchers to record that palliative care nurses viewed dying alone as undesirable and felt equally that it was important to "be with a dying person" at their moment of death so that dying people knew that "someone cares". This sentiment is echoed in recent writing by Gelo (2004) and McKee and colleagues (2007). Smith-Reese (2005), for example, although insisting that patients have a right to shape their own way of dying, nevertheless advocates this to be facilitated by technologies that perform "in-home monitoring", medallions that provide help call services and machines that assist with "medication compliance". If some older people feel uncomfortable with professionals in their own homes when dying (Gott et al. 2004), it is difficult to imagine what this same group would make of these newer forms of surveillance (Seale 1996). The UK study by the Centre for Policy on Ageing (Howse 1997: 19-22) identifies a sample of what neighbours describe as "hermits" and "loners" and what the report describes as "service refusers". These are negatively described as people who kept to themselves, "refused" to open doors or receive social or health care workers. Even individuals who displayed clarity of mind and purpose, such as a 93-year-old woman discharging herself to her home after a heart attack ("she insisted on discharge" reads this report), is included under the category of "service refusers" (Howse 1997: 22). Klinenberg's (2001) emergency service workers in his US study make similar charges - these dying people were often "reclusive", "kept to themselves" and never "opened their doors". Those who die alone in these 
International Journal of Ageing and Later Life

storylines are pictured as anti-social, fearful, lonely, even pathetic figures who need help despite themselves or their lifestyles.

\section{Tragics}

The media are most fond of this social image. Here, those who die alone are considered the "forgotten" (Adams \& Johnson 2008). People who die alone are tragic figures - either they have lived a life as a social failure, without love, respect or social accomplishments, or they have been isolated through no fault of their own and it is "society" that has cruelly withdrawn its supportive social web or canopy from them (Seale 2004: 973). The media will frequently select the more sensational types of dying alone - suicide, drug overdose, murder or elderly persons found dead some years after they had died alone in their flat or house (Lishman 2009; Seale 2004: 969). There will be outrage, questions asked, calls for investigation, review or new actions, all very reminiscent as Seale (2004) argues, of anthropological accounts of witch-hunts following what the community declares as a "bad death". Family and friends of those who have died alone have also contributed their share of resentment and detail of their own "tragic" loved ones who had died alone remembering them as "being difficult", stubborn, awkward, "not easy to get on with" and more bitterly, as people who "failed to be sufficiently grateful" (Seale 1996: 86).

\section{Self-destructors}

The idea that those who die alone may be more responsible for their miserable fate than an uncaring society has some support from the academic literature. Gove and Hughes (1980), for example, wrote a major review article that linked living alone with similar morbidity and mortality data from suicides, alcoholics and those in psychiatric treatment. They asserted that, "there is a substantial body of evidence which indicates that living alone is correlated with a wide variety of pathological phenomena" (Gove and Hughes 1980: 1160). The review links living alone with drinking or depression and these, in their turn, may be an outcome or consequence of deeper personality and behaviour problems. They advocate more empirical research into several of their own hypotheses about people who live alone including the idea that "social control of behaviour requires 
Dying old - and preferably alone?

social interaction and the isolated individual, lacking such control, will be free to act in deviant ways" (Gove \& Hughes 1980: 1173). Linked to other portrayals of those dying alone as tragics, these ideas compound and exaggerate the stigma of living and dying alone (Seale 2004); increase the pressure on surveillance of the elderly who live alone (Seale 1996), as well as helping reinforce views that single older people might be better off in institutions such as hospitals or care homes - in fact, places that are not guarantees for more peaceful or less lonely deaths anyway (Bradshaw et al. 1977: 23).

The idea that people who live and die alone are social misfits and deviants - loners, lonelies, tragics and self-destructors - obscures and distracts our gaze away from the greater sociological facts of this form of death and lifestyle. People who live alone are increasing, especially among the very old, and anyway represent a significant proportion of all people who live in affluent, urban communities. So many of the elderly fear crime (Age Concern 2008; Klinenberg 2001), or are so regularly preyed upon by unscrupulous salespeople, neighbourhood deviants or hustlers, or have heard so much about others who have fallen victim to these types, that many do barricade themselves or withdraw into their flats and houses. These people hole up in their residence seeing few people, confining themselves to TV, phone buddies or their mail. If they are affluent, this only increases their ability to go out less as they can order most things in or be provided services in their own homes (Krivo \& Mutchler 1989).

Other observations about the end of life preferences of the elderly also do not square with the available negative social categories and explanations of people who die alone. Kelner (1995), for example, studied hospitalised elderly people's preferences about "control at the end of life" and found that he could divide the responses into "activists" and "delegators". Activists were people who desired control as opposed to delegators who were more than happy for other agents such as God, fate or doctors to take control. Activists were a 2:1 majority. How are people who are "activists", people who take control, accounted for among those who live - and die - alone? Are we to believe that those who die alone are unrepresentative? No empirical evidence to support that conclusion seems available. A review of elderly views about the end of life does suggest a further range of social decisions or circumstances that can logically and 
International Journal of Ageing and Later Life

understandably lead to dying alone as forms of self-control (agency), resistance and dissent.

\section{Prominent Elderly Perspectives on "Dying Alone"}

Studies of death and dying from older people's point of view are sparse (Hallberg 2004) but what we do have is insightful, although the vast majority of these studies have small samples. If for example, you ask older people about what a "good death" might look like for them (Gott et al. 2008; Howarth 1998; Lloyd-Williams et al. 2007; Steinhauser et al. 2000; Vig et al. 2002), some consistent themes do emerge. Howarth (1998) found among her 42 respondents a desire for quick death, preferably without much pain and a desire for autonomy and control. Steinhauser and colleagues (2000) found among their 72 respondents of professionals, families and older people the themes of good symptom management, preparation, sense of life completion and the affirmation of a person's life. All of these themes are not incompatible with a death or dying at home with or without palliative care.

Lloyd-Williams and colleagues (2007) found similar themes among their 40 interviewees adding that fear of becoming a burden was also one of the issues that concerned their sample of over 80s. The studies by Vig and colleagues (2002) and by Gott and colleagues (2008), with samples of 16 and 40, respectively, did not find clear themes and also uncovered some paradoxes. But even they observed concerns about the desire to avoid any "debasing" processes involved in prolonged illness, institutionalisation or even families being present when they died. Again, these issues are also not inconsistent with a desire to be at home and to die at home - alone. Some of these issues can actually act to promote the idea that death at home and alone would be an act of agency and control because such a death or dying would avoid or postpone institutionalisation and constant surveillance while affirming their own identity and lifestyle.

Fear, for example, is a significant feature of older people's lives - fear of crime, fear for one's safety in public places, fear of loss of control and fear too of any threat to one's self-esteem (Fry 1990). Many of these fears, as we have seen explained in Klinenberg's (2001) US study and the data collected by Age Concern (2008) in the UK suggest that older people might cope by 
Dying old - and preferably alone?

withdrawal into their homes, seeking support remotely (by phone) or through prayer and pre-occupation with home activities and objects (Fry 1990). Fear of being a burden is also a re-occurring concern (Gott et al. 2008; Lloyd-Williams et al. 2007). Hallberg (2004) in reviewing 33 empirical studies of death and dying from older people's point of view argued that fear of being a burden is another way of manifesting a fear of dependency. This in turn encourages people to maintain their independence for as long as possible, perhaps appearing to others as people who are "private", "reclusive" or "keeping to themselves".

But there is little doubt that living alone does not necessarily mean socially isolated as many people who are able to visit and be visited do so. Winter and colleagues (2007), for example, found in their sample of 40 people in their 70s that most desired active treatment if they were dying. Social interaction was an important idea associated with a "good death" for them. These authors go on to suggest that perhaps the desire rather than simply the necessity of active medical treatments were suggestive of a desire to be with others. If that is true the reverse may be true also, so that the so-called "service refusers" in the 1997 Centre for Policy on Ageing represent a desire to simply be left alone. The ability to exercise that choice, and live with that preference, is an example of personal agency and autonomy par excellence. For some of the very old, for example, there is no "quality of life" to be had or to be recaptured when most of your friends and loved ones have predeceased you (Farquhar 1995). This is a particularly important point when successive researchers of quality of life have recognised the importance of social relationships over health, medical or other physical issues for most of the elderly (Carmel 2001; Farquhar 1995; Victor et al. 2004).

A significant ("significant", that is, enough to appear as a few respondents in small studies) number of older voices believe they are just filling in time till they die (Farquhar 1995; Kim et al. 2008; Owen 2005). And although Cicirelli (1998) found that most of his 447 elderly respondents "strive to live" (52\%), a sizeable minority find suicide an acceptable idea (31\%). Such underlying values tell us something more than that the high suicide rate among the elderly is simply and only about depression (Cattell 2000; Kellehear 2007). Even older homeless people express a fear of dying alone and in the streets ( $\mathrm{O}^{\prime}$ Connell 2005), but many 
International Journal of Ageing and Later Life

do die alone in the streets anyway and not all of these can be rationalised as accidental. As even $\mathrm{O}^{\prime}$ Connell observes alongside this earlier point, homeless people often give "aliases" - an old identity has already died, or is dying alone. And these are decisions made - rightly or wrongly, with some reservations or none - of people who choose to adopt this kind of end of life lifestyle.

Together, all these social influences suggest that the decision to live and die at home alone, has understandable and practical factors that underpin them - from fear of crime and dependency, to an idiosyncratic interpretation of a "good death" without others that satisfies some personal idea of affirmation of their own life both among the housed and even the homeless. Some desire professional contact but yet others find their generation gone and simply lose interest in a world that has little or nothing to offer them. Dying at home alone may represent a personal sense of agency and a resistance towards the threat of increasing surveillance, dependency or institutionalisation. For some, even a small some, dying alone in suffering, or by suicide in their own homes, may represent dissent or a refusal to take the meagre social care choices offered to them.

\section{Conclusion}

When we review the diverse views of the elderly about the end of life, we are forced either to believe that those who die alone are unrepresentative of that diversity (by virtue of their flawed character as Gove \& Hughes 1980 argue); or that we have not managed to interview them (as Klinenberg 2001 suggest might be happening); or that we have the actual data that includes them but, as I have already suggested, have obscured those facts with negative over-generalisations. Until there is genuine evidence that those who die alone truly do represent the lonely, tragic and selfdestructive elements of an older society, we must look to the latter two possibilities.

There are methodological challenges in reaching groups who do not wish to be reached but the early work of Seale (1996) in interviewing family and friends, seeing past their rationalisations of guilt and regret to gain access to modest images of the people who died alone have further, 
Dying old - and preferably alone?

future promise. In this regard, promising also will be the identification and use of any records left by the dying such as last testimonies, suicide notes or diaries, to give us further clues to the values and decisions that these people make in charting their life and dying styles.

As for the possibility of already having the data but recognising neither the diversity nor the positive nature of some of this solitary conduct at the end of life, we can only take the caution offered us by most ethnographers and grounded theorists. We depart from the voices and experiences of those we wish to study at our own peril. And if those voices or experiences are difficult to access, they are by no means unreachable, however contested might be their subsequent interpretation. A set of conclusions about the conduct of other people that is consistently negative and disempowering suggests that either the reading or the data is compromised. The choice of what to do suggests itself - it is easier to re-visit the reading if the data available is unavoidably limited and preciously slim.

The experience of dying alone, even if this is not associated with loneliness or social isolation, is not incompatible with compassionate views and questioning about failure of care. Clearly, the sociological and policy dilemmas and complexities surrounding the care of the elderly, at a time when we are at the commencement of a major rise in this population, is of major and legitimate concern. But this social compassion and moral responsiveness neither should be uncritical of social differences, nor minimise the growing community perception that choices are few for most older people, and even less for the poor.

Occupational, ethnic, spiritual and even cohort differences between older people make institutional care of every sort a highly threatening prospect that appears dull at best, frightening at worst (Elias 1985; Millar 2003). It is important to attune our understandings to these social differences and preferences and this must start with a more nuanced dissection of the empirical findings about those who die alone, however limited those data may be. This is only a call for a more thoughtful and pluralist interpretation of older person's actions at the end of life when we attempt readings for this kind of data.

Critical observations of a poor fit between elderly views of end of life care and the common observations about dying alone also suggest an important and timely caution against theoretically positioning of all 
International Journal of Ageing and Later Life

elderly people as "victims". Although it is true that many older people wish to be taken care of by their health and social care establishments and authorities, and do feel abandoned and victimised if they are not (Gott et al. 2008), many others do not share these sentiments (Kelner 1995).

Increasingly, the more affluent and educated older person does not desire this paternalism. As Hallberg (2004) and some older persons speaking through Owen's (2005) work suggest, many dying people do not fear death, are prepared for death and are resigned to dying, but desire above all their autonomy and value any attempts, either formal or informal, to maintain that independence. Dying old, and alone, is a small demographic outpost of the mortality statistics in any country but its scrutiny may prove to be valuable sociological ground. For those of us interested in an inclusive vision of end of life care, the study of lone dying may provide a conveniently containable research front in which to witness and witness with unrivalled clarity - conflicts of interests over the age-old problem of mortality.

\section{Corresponding Author}

Allan Kellehear, Department of Social \& Policy Sciences, University of Bath, Bath BA2 7AY, UK. Email: a.kellehear@bath.ac.uk

\section{References}

Adams, J. \& Johnson, J. (2008). Older people 'found dead' at home: Challenges for the coroner system in England and Wales. Mortality 13(4): 351-360.

Age Concern. (2008). Older People in the United Kingdom: Key Facts and Statistics 2008. London: Age Concern.

Bradshaw, J., Clifton, M. \& Kennedy, J. (1977). Found dead: A study of old people found dead. Age Concern, Occasional Paper \#5.

Carmel, S. (2001). The will to live: Gender differences among elderly persons. Social Science \& Medicine 52: 949-958.

Cattell, H. (2000). Suicide in the elderly. Advances in Psychiatric Treatment 6: $102-108$.

Cicirelli, V. G. (1998). Views of elderly people concerning end of life decisions. Journal of Applied Gerontology 17(2): 186-203. 
Dying old - and preferably alone?

Dunnel, K. (2008). Ageing and mortality in the UK. Population Trends 134: 6-23.

Elias, N. (1985). The Loneliness of the Dying. Oxford: Blackwell.

Farquhar, M. (1995). Elderly people's definitions of quality of life. Social Science \& Medicine 41: 1439-1446.

Field, D. (1984). We didn't want him to die on his own - nurses accounts of nursing dying patients. Journal of Advanced Nursing 9: 59-70.

Fry, P. S. (1990). A factor analytic investigation of home bound elderly individuals' concerns about death and dying and their coping responses. Journal of Clinical Psychology 46(6): 737-748.

Gelo, F. (2004). Dying alone with the TV. American Journal of Hospice and Palliative Medicine 21(3): 167-168.

Gott, M., Seymour, J., Bellamy, G., Clark, D. \& Ahmedzai, S. (2004). Older people's views about home as a place of care at the end of life. Palliative Medicine 18: 460-467.

Gott, M., Small, N., Barnes, S., Payne, S. \& Seamark, D. (2008). Older people's views of a good death in heart failure: Implications for palliative care provision. Social Science \& Medicine 67: 1113-1121.

Gove, W. R. \& Hughes, M. (1980). Re-examining the ecological fallacy: A study in which data are critical in investigating the pathological effects of living alone. Social Forces 58(4): 1157-1177.

Gurley, R. J., Lum, N., Sande, M., Lo, B. \& Katz, M. H. (1996). Persons found in their homes helpless or dead. New England Journal of Medicine 334(26): 1710-1716.

Hallberg, I. R. (2004). Death and dying from older people's point of view: A literature review. Aging Clinical and Experimental Research 16(2): $87-102$.

Hamiltby, G. B. (2000). Loneliness in Later Life. New York: Palgrave.

Howarth, G. (1998). 'Just live for today': Living, caring, ageing and dying. Ageing and Society 18: 673-689.

Howse, K. (1997). Deaths of People Alone. London: Centre for Policy on Ageing. And also: Centre for Policy on Ageing. (1997). Dying Alone: Interim Results from a Study of Coroners' Records in Southwark and Waltham Forest. London: Centre for Policy on Ageing.

Kellehear, A. (2007). A Social History of Dying. Cambridge: Cambridge University Press. 
International Journal of Ageing and Later Life

Kelner, M. (1995). Activists and delegators: Elderly patients' preferences about control at the end of life. Social Science $\mathcal{E}$ Medicine 41: 537-545.

Kim, C., Ko, M. H., Kim, M. J., Kim, J., Kim, H. J., Moon, J. H., Baek, K. S., Son, H., Oh, S., Lee, Y. \& Choi, J. S. (2008). The life of elderly women living alone. Journal of the Korean Academy of Nursing 38(5): 739-747.

Klinenberg, E. (2001). Dying alone: The social production of urban isolation. Ethnography 2(4): 501-531.

Krivo, L. J. \& Mutchler, J. E. (1989). Elderly persons living alone: The effect of community context on living arrangements. Journal of Gerontology: Social Sciences 44(2): 554-562.

Leishman, J. (2008). Older people, death, dying and end of life care. Quality in Ageing 9(4): 36-43.

Lishman, G. (2009). Our Response to the Case of Ken Mann Found Dead After 6 Years. London: Age Concern England.

Lloyd-Williams, M., Kennedy, V., Sixsmith, A. \& Sixsmith, J. (2007). The end of life: A qualitative study of the perceptions of people over the age of 80 on issues surrounding death and dying. Journal of Pain and Symptom Management 43(1): 60-66.

McKee, M., Kelley, M. L. \& Guirguis-Younger, M. (2007). So no one dies alone: A study of hospice volunteering with rural seniors. Journal of Palliative Care 23(3): 163-172.

Millar, M. (2003). You just shed life: A nursing home resident talks about the future. In A. Kellehear \& D. Ritchie (eds.), Seven Dying Australians (pp. 24-34). Bendigo, VIC: Innovative Resources.

National Statistics. (2002a). Social Trends 31:2002. Available on www. statistics.gov.uk (Accessed: March 27, 2009).

National Statistics. (2002b). Social Trends 32:2002. Available on www. statistics.gov.uk (Accessed: March 27, 2009).

O'Connell, J. J. (2005). Raging against the night: Dying homeless and alone. Journal of Clinical Ethics 16(3): 262-266.

Owen, T. (ed.) (2005). Dying in Older Age: Reflections and Experiences from an Older Person's Perspective. London: Help the Aged.

Roy, D. J. (2003). Editorial: When people die alone ... a meditation on humanity. Journal of Palliative Care 19(4): 227-228.

Seale, C. (1995). Dying alone. Sociology of Health \& Illness 17(3): 376-392. 
Dying old - and preferably alone?

Seale, C. (1996). Living alone towards the end of life. Ageing and Society 16: 75-91.

Seale, C. (2004). Media constructions of dying alone: A form of 'bad death'. Social Science \& Medicine 58: 967-974.

Smith-Reese, J. (2005). The gift of dying at home alone. Caring 24(11): 62-66, 68.

Steinhauser, K. E., Clipp, E. C., McNeilly, M., Christakis, N. A., McIntyre, L. M. \& Tulsky, J. A. (2000). In search of a good death: Observations of patients, families, and providers. Annals of Internal Medicine 132(10): 825-832.

Tomassini, C., Glaser, K., Wolf, D. A., Brouse van Groenau, M. I. \& Grundy, E. (2004). Living arrangements among older people: An overview of trends in Europe and the USA. Population Trends 115(Spring): 24-34.

Tunstall, J. (1966). Old and Alone: A Sociological Study of Old People. London: Routledge and Kegan Paul.

Victor, C. R., Scambler, S. J. \& Bond, J. (2009). The Social World of Older People: Understanding Loneliness and Social Isolation in Later Life. New York: Open University Press.

Victor, C. R., Scambler, S. J., Bond, J. \& Bowling, A. (2004). Loneliness in later life. In A. Walker \& C. Hagan Hennessy (eds.), Growing Older: Quality of Life in Old Age (pp. 107-126). New York: Open University Press.

Vig, E. K., Davenport, N. A. \& Pearlman, R. A. (2002). Good deaths, bad deaths, and preferences for end of life: A qualitative study of geriatric outpatients. Journal of the American Geriatrics Society 50: 1541-1548.

Weeks, D. J. (1994). A review of loneliness concepts with particular reference to old age. International Journal of Geriatric Psychiatry 9: 345355.

Winter, L., Parker, B. \& Schneider, M. (2007). Imagining the alternatives to life prolonging treatments: Elders' beliefs about the dying experience. Death Studies 31: 619-631. 